\title{
Perancangan In Store Media Sebagai Inovasi Media Promosi Couple Distro
}

\author{
Adita Ayu Kusumasari \\ ${ }^{1}$ Prodi Desain Komunikasi Visual, STIKI Malang \\ adita.kusumasari@stiki.ac.id
}

\begin{abstract}
ABSTRAK
Bisnis fashion saat ini mengalami perkembangan yang cukup pesat. Hal tersebut ditandai dengan maraknya produk fashion yang inovatif dan berkualitas serta memiliki berbagai penganut fashion yang setia. Pergeseran paradigma terhadap fungsi dari pakaian juga terjadi, pakaian tidak hanya berfungsi untuk menutupi dan melindungi tubuh namun sebagai cerminan kepribadian, gaya hidup, dan status sosial. Hal tersebut memiliki dampak yang cukup luas terhadap industri fashion yang ada di Indonesia, khususnya distro. Kata distro merupakan singkatan dari distribution outlet yang menjual berbagai macam produk fashion. Couple Distro merupakan salah satu distro yang berada di Kota Malang. Couple Distro dapat menjadi salah satu alternatif pilihan fashion di Kota Malang. Metode TOWS digunakan untuk menganalisis data yang telah dikumpulkan dan akan digunakan sebagai konsep untuk perancangan. Tujuan dari penelitian ini adalah untuk melakukan perancangan hang tag kaos, hang tag aksesoris, hanger kaos, kartu nama, nota penjualan, packaging box, stuffler, shopping bag, flyer, dispenser flyer, pin, mini banner, $\mathrm{x}$ banner, poster in store, katalog in store, seragam store assistant, desain meja kasir, fitting room, window display, interior display, dan meja ekterior, hal tersebut dilakukan dengan harapan dapat meningkatkan penjualan Couple Distro.
\end{abstract}

Kata Kunci: In store media, promosi, TOWS, distro.

\begin{abstract}
Fashion business is currently experiencing rapid development. This is marked by proliferation of innovative and quality fashion products and a variety of loyal fashion followers. A paradigm shifts towards the function of clothes occurs, clothes function does not only to cover and protect the body, but as a reflection of personality, lifestyle, and social status. This has a broad impact on the fashion industry in Indonesia, especially distro. The word distro stands for various kinds of fashion products. Couple Distro is one of the distro located in Malang City. The TOWS method is used to analyze data that has been collected and will be used as a concept for design. The purpose of this study was to design t-shirt hang tags, hang tag accessories, shirt hangers, business cards, sales notes, packaging boxes, stuffler, shopping bags, flyers, flyer dispensers, pins, mini banners, $x$ banners, poster in stores, in store catalog, store assistant uniform, cashier table design, fittings room, window display, interior display, and exterior table. It was done to increase Couple Distro's sales.
\end{abstract}

Keywords: In store media, promotion, TOWS, distro.

\section{PENDAHULUAN}

Industri bisnis fashion saat ini mengalami perkembangan yang sangat pesat (Hadijah, 2014). Hal ini ditandai dengan banyaknya produk-produk fashion yang inovatif dan berkualitas. Pada awalnya fungsi dari pakaian adalah untuk menutupi bagian-bagian tubuh, namun seiring perkembangan zaman terdapat pergeseran dari fungsi pakaian itu sendiri, yaitu untuk cerminan kepribadian, gaya hidup, dan status sosial (Global \& Jurnalistik, 2017).

Perkembangan industri fashion di Kota Malang berkembang cukup pesat dari waktu ke waktu. Hal ini ditunjukkan dengan keberadaan distro yang memiliki clothing company sendiri. Tren munculnya distro di Kota Malang dimulai sekitar tahun 2003 yang sebagian besar masih menjual berbagai produk dari clothing company asal Kota Bandung. Beberapa merk asli pabrikan clothing company yang berada di Kota Malang mulai dikenal dan mampu 
menunjukkan identitasnya masing-masing. Hal tersebut membuat persaingan antar distro di Kota Malang menjadi sangat bersaing (Nugroho, Widarko, \& Priyono, 2016).

Couple Distro adalah salah satu distro yang ada di Kota Malang yang merupakan salah satu distro yang memberikan konsep yang berbeda dan cukup menarik perhatian pembeli. Couple Distro menawarkan berbagai produk fashion apparel berpasangan. Selain itu gaya desain yang diusung oleh distro tersebut cenderung minimalis dan berwarna yang menjadi ciri khas produk distro tersebut dibandingkan dengan produk distro yang lain. Namun Couple Distro sebagai pendatang baru masih membutuhkan media komunikasi visual yang mampu mengkomunikasikan serta menanamkan brand image Couple Distro terhadap target pasar, target audien, dan khalayak yang berhubungan. Media promosi bersifat sangat penting bagi menunjang kegiatan pemasaran.

In store media diaplikasikan untuk menampilkan brand image dari produk clothing serta desain produk fashion apparel yang dikemas secara menarik yang diharapkan mampu memicu impulse buying bagi pelanggan yang datang di Couple Distro serta meningkatkan brand image dapat tertanam dnegan kuat di benak target market, target audiens serta khalayak yang relevan.

\section{PEMBAHASAN}

Adapun metode perancangan yang digunakan merujuk pada kerangka perancangan Drs. Sadjiman Ebdi Sanyoto (Sanyoto, 2006) dengan beberapa penyesuaian terdapat pada Gambar 1 .

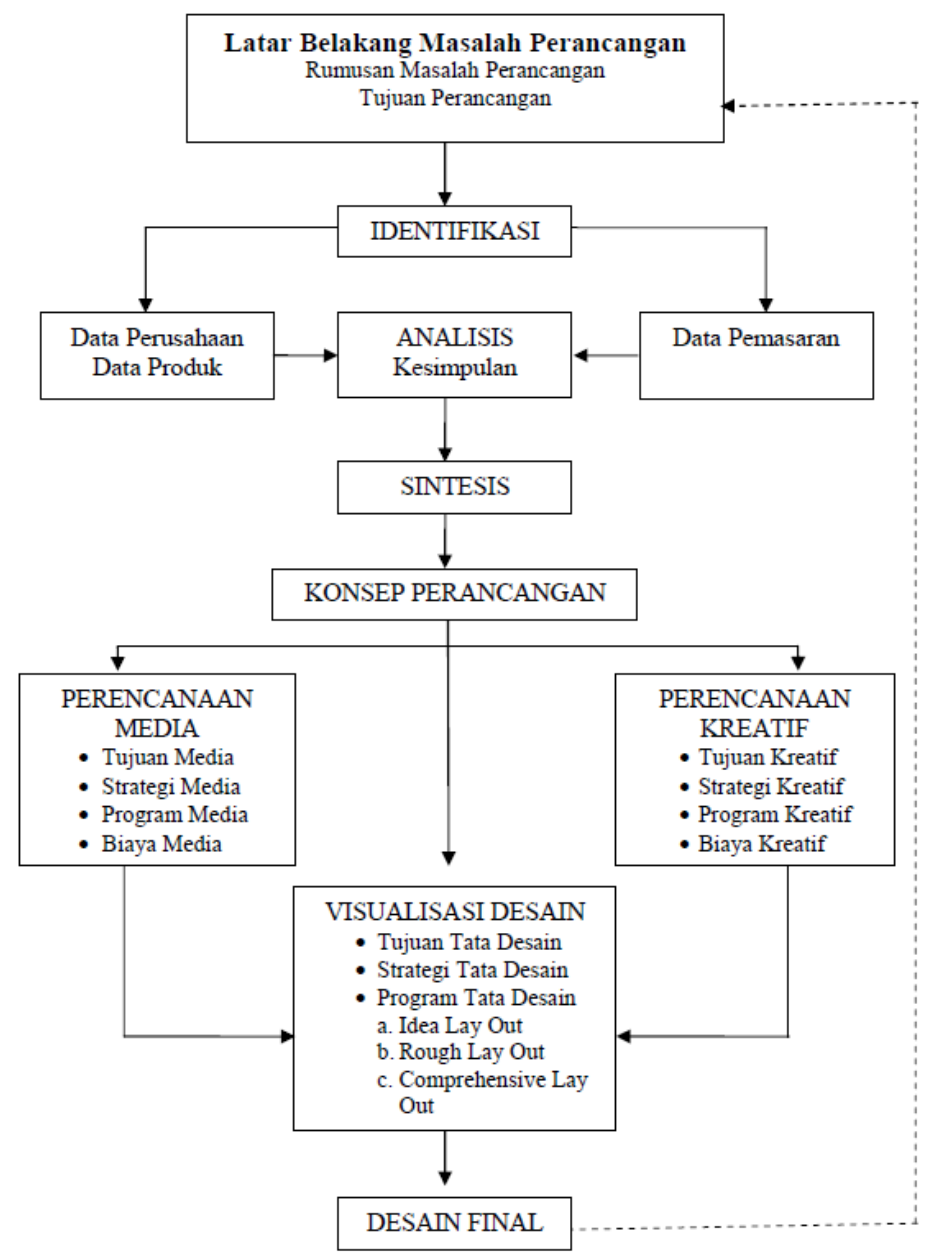

Gambar 1. Kerangka Perancangan Sadjiman Ebdi Sanyoto 
Secara umum prosedur perancangan penelitian menggunakan beberapa tahap, antara lain: observasi, wawancara dan dokumentasi.

\section{a) Observasi}

Observasi yang dipergunakan dalam perancangan ini adalah observasi non sistematis, yang dilakukan dengan tidak menggunakan instrumen pengamatan (Hasanah, 2017). Observasi dilakukan oleh peneliti untuk memperoleh data yang belum didapat melalui teknik wawancara dengan mengamati obyek penelitian. Adapun obyek yang akan diteliti adalah kondisi fisik, jenis-jenis produk, ciri khas, karakteristik hingga penempatan media komunikasi visualnya.

\section{b) Wawancara}

Metode wawancara yang digunakan adalah wawancara bebas terpimpin, dimana dalam pelaksanaannya, peneliti membawa pedoman wawancara yang merupakan garis besar tentang hal-hal yang akan ditanyakan (Hakim, 2013). Instrumen pengumpulan data dalam metode wawancara ini berupa pedoman wawancara (interview guide). Jenis wawancara yang digunakan adalah wawancara terbuka yaitu wawancara dimana subjek yang diwawancara tahu bahwa mereka sedang diwawancarai dan tahu pula maksud dari wawancara itu. Wawancara dilakukan langsung antara peneliti dan subyek yang diteliti yaitu owner Couple Distro.

\section{c) Dokumentasi}

Metode dokumentasi dalam perancangan ini dilakukan untuk memperoleh informasi melalui benda-benda tertulis seperti catatan-catatan dan dokumen (Sudarsono, 2017). Instrumen yang digunakan dalam metode ini adalah checklist yang berfungsi untuk mencatat variabel yang telah ditentukan. Adapun data dokumentasi yang diperlukan berupa: beberapa media komunikasi visual yang telah ada, berbagai data tertulis seperti company profile, distribusi serta daftar harga produk, dan berbagai data pemasaran.

\section{Identifikasi Data}

Identifikasi data sebagai bagian dari sistematika sebuah laporan perancangan merupakan proses yang memiliki tujuan untuk mengidentifikasi semua data dari hasil survey. Identifikasi data meliputi: data perusahaan (nama produk, nama perusahaan, lokasi, dan data lain dari perusahaan yang mendukung perancangan). Nama produk yang dijual adalah Couple.
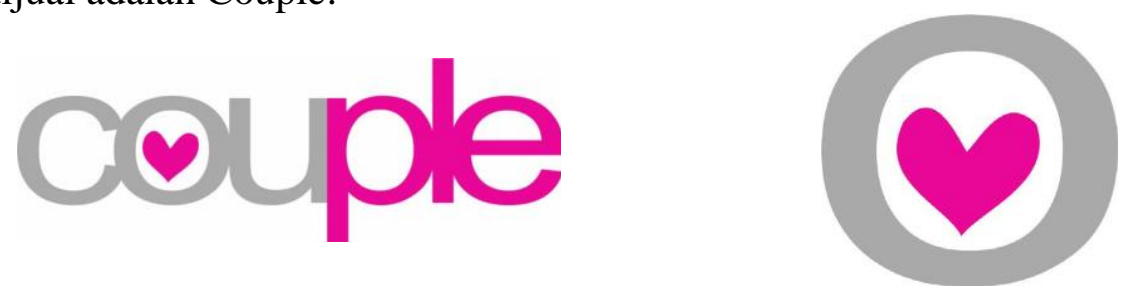

Gambar 2 Word Marks dan Device Marks 
Menurut hasil wawancara dengan pemilik, arti word marks dan device marks adalah sebagai berikut:

- Kata couple diambil dari kata dalam bahasa inggris yang memiliki arti yaitu pasangan.

- Menggunakan perpaduan dua warna, yaitu warna abu-abu untuk melambangkan lakilaki sedangkan warna magenta untuk melambangkan perempuan, karena produk yang dijual berupa produk berpasangan untuk remaja laki-laki dan perempuan.

- Pada device marks merupakan bagian dari word marks yang berdiri sendiri dengan bentuk lingkaran berwarna abu-abu dan bentuk hati berwarna magenta yang merupakan warna korporat. Bentuk hati berwarna magenta berada dalam bentuk lingkaran berwarna abu-abu melambangkan hubungan antara laki-laki dan perempuan dimana laki-laki melindungi perempuan pasangannya.

- Secara keseluruhan word marks dan device marks dari Couple Distro adalah melambangkan laki-laki dan perempuan yang memiliki hubungan.

1. Nama Perusahaan

Nama Perusahaan adalah Couple Distro, merupakan distro yang menjual produk clothing merk Couple yang memiliki konsep fashion apparel berpasangan.

2. Lokasi

Couple Distro beralamat di Ruko Hamid Rusdi Kav. 3, Kota Malang, Jawa Timur. Secara lebih detail lokasi Couple Distro terdapat pada gambar 4 dibawah ini.

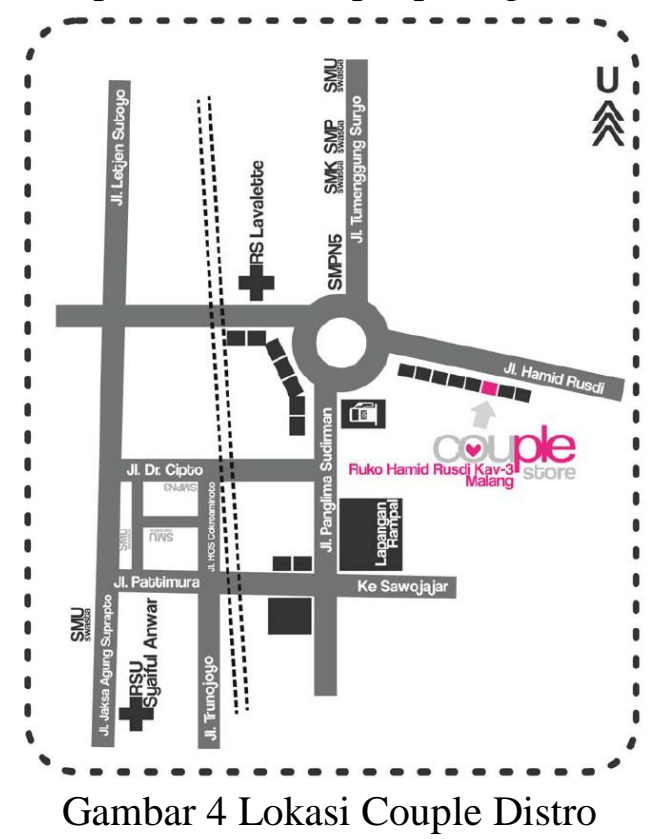

3. Data Produk (jenis produk, bahan baku, merk perusahaan, kemasan, harga, dll.)

4. Produk

Menurut hasil wawancara dengan pemiliki Couple Distro, produk yang dijual adalah produk fashion dan aksesoris dengan konsep berpasangan. Mulai dari kaos, kemeja, celana, jaket, jumpet dan vest.

5. Harga Produk

Berdasarkan observasi yang telah dilakukan, diperoleh data berupa harga produk sebagai berikut. 
Tabel 1. Harga Produk Couple Distro

\begin{tabular}{lcc}
\hline \hline No & Produk & Harga \\
\hline 1. & Kaos berpasangan & Rp. $180.000,-$ \\
2. & Polo shirt berpasangan & Rp. 85.000,- \\
3. & Celana panjang wanita & Rp. 130.000,- \\
4. & Celana pendek wanita & Rp. $90.000,-$ \\
5. & Rok wanita & Rp. 95.000,- \\
6. & Vest wanita & Rp. 85.000,- \\
7. & Jaket pria & Rp. $130.000,-$ \\
8. & Tas pria & Rp. $150.000,-$ \\
9. & Vest pria & Rp. $90.000,-$ \\
10. & Celana pendek pria & Rp. $110.000,-$ \\
\hline \hline
\end{tabular}

\section{Data Pemasaran}

Pada data pemasaran mencakup posisi pasar, potensi pasar, segmentasi pemasaran, promosi yang dilakukan, kompetitor, dll. Berdasarkan data dokumentasi yang ada, sejak dibuka pada bulan Agustus 2008 telah dilakukan beberapa promosi periklanan. Promosi yang telah dilakukan oleh Couple Distro adalah sebagai berikut:

- Event Sponshorship melalui acara ulang tahun sekolah menengah pertama.

- Iklan Radio melalui salah satu radio yang berada di Kota Malang.

- Print Media berupa poster, flyer, sticker, dan poster.

- Hang Tag

- Name Card

- Branding Produk

- Segmentasi Pasar

Tabel 2. Segmentasi Pasar Couple Distro

\begin{tabular}{lcc}
\hline \hline No & Demografi & Kriteria \\
\hline 1. & Jenis Kelamin & Laki-laki; Perempuan \\
2. & Usia & $15-25$ tahun \\
3. & Pendidikan & SMP;SMA;PT \\
4. & Pekerjaan & Pelajar;Pegawai \\
5. & Status Pernikahan & Belum Menikah; Sudah Menikah \\
6. & Jumlah Pengeluaran & Rp. 1.000.000-1.500.000,- \\
7. & Sikap Terhadap Produk & Positif \\
\hline
\end{tabular}

\section{Analisis Data}

Mengolah data berarti menimbang, menyaring, mengatur, dan mengklasifikasikan data. Metode analisis data yang digunakan dalam menganalisis data yang telah 
dikumpulkan sebelumnya adalah menggunakan analisis TOWS yang merupakan jenis baru dari analisis SWOT (Mashadi, Tinggi, \& Ekonomi, 2019). Kelebihan dari analisis TOWS adalah pada tabel TOWS menggabungkan antara faktor-faktor yang ada untuk membentuk strategi pemasaran.

Berdasarkan dari data yang telah dikumpulkan kemudian dilakukan analisis data menggunakan metode TOWS yang nantinya dapat dijadikan dasar untuk memilih strategi yang dinilai paling tepat dalam perancangan konsep media dalam perancangan ini. Adapun hasil analisis menggunakan metode SWOT terdapat pada tabel 3 dibawah ini.

Tabel 3 Analisis SWOT

\begin{tabular}{|c|c|c|c|}
\hline Strength & Weakness & Opportunities & Threat \\
\hline $\begin{array}{l}\text { Konsep unik dan } \\
\text { berbeda dengna konsep } \\
\text { fashion apparel } \\
\text { berpasangan }\end{array}$ & $\begin{array}{r}\text { - Sempit dan } \\
\text { spesifiknya } \\
\text { target pasar }\end{array}$ & - Menjadi trendsetter & $\begin{array}{l}\text { - } \text { Munculnya } \\
\text { kompetitor }\end{array}$ \\
\hline $\begin{array}{l}\text { - Pertama dan satu- } \\
\text { satunya }\end{array}$ & $\begin{array}{l}\text { - Pendatang } \\
\text { baru }\end{array}$ & $\begin{array}{l}\text { - } \text { Memiliki } \\
\text { kesempatan } \\
\text { menguasai pasar }\end{array}$ & $\begin{array}{l}\text { - } \text { Munculnya } \\
\text { produk tiruan }\end{array}$ \\
\hline
\end{tabular}

- Belum ada kompetitor langsung

Dari analisis SWOT diatas dilakukan alternatif strategi SO (Strengths and Opportunities), alternatif strategi ST (Strengths and Threats), alternatif strategi WO (Weaknesses and Opportunities) dan alternatif strategi WT (Waknesses and Threats), hasilnya terdapat pada tabel 4 dibawah ini.

Tabel 4 Analisis Menggunakan TOWS

\begin{tabular}{|c|c|c|c|}
\hline $\begin{array}{l}\text { Alternatif Strategi } \\
\text { SO }\end{array}$ & $\begin{array}{c}\text { Alternatif Strategi } \\
\text { WO }\end{array}$ & $\begin{array}{c}\text { Alternatif Strategi } \\
\text { ST }\end{array}$ & Alternatif Strategi WT \\
\hline $\begin{array}{l}\text { Konsep unik dan } \\
\text { berbeda dengan } \\
\text { konsep apparel } \\
\text { berpasangan } \\
\text { harus dapat } \\
\text { dikomunikasikan } \\
\text { agar dapat } \\
\text { menimbulkan } \\
\text { rasa penasaran } \\
\text { target pasar }\end{array}$ & $\begin{array}{l}\text { Harus mampu } \\
\text { menjadi } \\
\text { trendsetter dalam } \\
\text { spesifiknya target } \\
\text { pasar }\end{array}$ & $\begin{array}{l}\text { - Secara maksimal } \\
\text { mengkomunikasi } \\
\text { kan konsep unik } \\
\text { dan berbeda dari } \\
\text { Couple Distro }\end{array}$ & $\begin{array}{l}\text { - Menanamkan image } \\
\text { brand Couple Distro } \\
\text { sekuat mungkin } \\
\text { dalma sempitnya } \\
\text { target pasar }\end{array}$ \\
\hline $\begin{array}{l}\text { - Harus } \\
\text { melakukan }\end{array}$ & $\begin{array}{l}\text { - Pendatang baru } \\
\text { harus mampu }\end{array}$ & $\begin{array}{l}\text { - Menanamkan } \\
\text { image brand }\end{array}$ & $\begin{array}{l}\text { - Mengkomunikasika } \\
\text { n secara tepat akan }\end{array}$ \\
\hline
\end{tabular}




\begin{tabular}{|c|c|c|c|}
\hline $\begin{array}{l}\text { komunikasi } \\
\text { periklanan } \\
\text { secara } \\
\text { menyeluruh }\end{array}$ & $\begin{array}{l}\text { mengkomunikasik } \\
\text { an keberadaannya }\end{array}$ & $\begin{array}{l}\text { Couple Distro } \\
\text { dalam benak } \\
\text { target audiens } \\
\text { sebagai distro } \\
\text { pertama dan } \\
\text { satu-satunya } \\
\text { dengan konsep } \\
\text { fashion apparel } \\
\text { berpasangan }\end{array}$ & $\begin{array}{l}\text { konsep yang unik } \\
\text { dan berbeda dari } \\
\text { Couple Distro di } \\
\text { dalam spesifiknya } \\
\text { target pasar }\end{array}$ \\
\hline $\begin{array}{l}\text { - Dapat menjadi } \\
\text { trendsetter } \\
\text { - Belum ada } \\
\text { kompetitor } \\
\text { langsung }\end{array}$ & $\begin{array}{l}\text { - Memaksimalkan } \\
\text { komunikasi } \\
\text { periklanan untuk } \\
\text { menanamkan } \\
\text { image brand } \\
\text { couple distro } \\
\text { dalam benak } \\
\text { target pasar }\end{array}$ & $\begin{array}{l}\text { Dengan kuatnya } \\
\text { image brand } \\
\text { Couple Distro } \\
\text { yang tertanam, } \\
\text { maka diharpakan } \\
\text { pelanggan tidak } \\
\text { tergoda }\end{array}$ & $\begin{array}{l}\text { - Sebagai pendatang } \\
\text { baru, melakukan } \\
\text { komunikasi } \\
\text { periklanan secara } \\
\text { tepat dan } \\
\text { menyeluurh untuk } \\
\text { menanamkan image } \\
\text { brand sekuat- } \\
\text { kuatnya sebelum } \\
\text { muncul kompetitor } \\
\text { langsung serta } \\
\text { kemungkinan } \\
\text { adanya produk } \\
\text { tiruan }\end{array}$ \\
\hline
\end{tabular}

Berdasarkan analisis TOWS yang telah dilakukan untuk memperkuat analisis pemasaran, diharapkan nantinya dapat dijadikan dasar pertimbangan memilih strategi yang dinilai paling tepat dalam perencanaan konsep media maupun konsep kreatif dalam perancangan. Sehingga diharapkan dengan adanya perancangan ini mampu memberikan solusi atas permasalahan yang dihadapi oleh Couple Distro.

\section{Sintesis}

Sintesis dalam perancangan ini adalah perpaduan dari permasalahan yang ada pada latar belakang masalah yang telah dirangkum ke dalam analisis. Sintesis dalam perancangan ini meliputi perencanaan pemasaran, perencanaan promosi, dan perencanaan periklanan.

\section{a) Tujuan Pemasaran}

Berdasarkan latar belakang masalah yang ada, terdapat tujuan pemasaran yang diharapkan, antara lain:

- Pengenalan produk baru

- Menjangkau target audiens 
- Menanamkan brand image

\section{b) Strategi Pemasaran}

Strategi pemasaran yang dilakukan untuk mencapai tujuan pemasaran adalah dengan mengambil langkah-langkah kebijakan terhadap paduan pemasaran yaitu:

- Product, packaging produk diperbarui dengan desain yang lebih menarik dan diharapkan mampu menampilkan brand image.

- Price, harga tetap biasa tidak ada perubahan.

- Place, distribusi belum dilakukan langkah perluasan, tetapi dilakukan penataan ulang interior dan eksterior Couple Distro agar tampil semakin menarik dan mengundang rasa ingin tahu target audiens terhadap produk-produk Couple Distro serta mampu menampilkan brand image

- Promotion, perencenaan promosi periklanan dalam bentuk perancangan komunikasi periklanan yang mampu mengenalkan produk, menjangkau target audiens, serta menanamkan brand image Couple Distro.

\section{c) Tujuan Promosi}

Berdasarkan siklus hidup produk (product life cycle) yaitu tahap awal atau baru (introductory), tahap pertumbuhan (growth), tahap matang (maturity), dan tahap kemerosotan (decline). Produk-produk Couple Distro termasuk pada tahap awal atau baru (introductory), maka tujuan promosi untuk perancangan ini adalah menimbulkan kesadaran dari target audiens terhadap produk-produk Couple Distro sampai kemudian timbul keinginan untuk membeli.

\section{d) Strategi Promosi}

Agar mencapai tujuan promosi Couple Distro, maka kebijakan yang diambil adalah paduan promosi (promotion mix) sebagai strategi promosi, yaitu:

- Publisitas (publicity) dan penjualan person (personal selling) belum mengambil langkah apa-apa.

- Promosi penjualan (sales promotion) dilakukan redesain visual merchandising dalam eksterior dan interior display pada Couple Distro agar mampu tampil lebih menarik dan mampu mengkomunikasikan image brand produk-produk Couple Distro.

- Periklanan (advertising) dilakukan komunikasi periklanan dengan strategi media dan strategi kreatif yang sesuai sehingga mampu menjangkau target audiens yang diharapkan mampu menimbulkan brand awareness target audiens terhadap produkproduk Couple Distro.

\section{e) Tujuan Komunikasi Periklanan}

Pada tujuan komunikasi periklanan Couple Distro mengacu pada advertising spiral. Advertising Spiral meliputi produk perintisan (pioneering), produk bersaing (competitive), dan produk mantap (retentive). Karena produk Couple Distro merupakan produk perintisan (pioneering), maka periklanan diharapkan adalah periklanan yang mampu menimbulkan kesadaran terhadap target audiens yang diharapkan agar target audiens mengetahui bahwa ada produk dan merk seperti yang diiklankan, kemudian mengetahui manfaat dan keunggulan produk yang diiklankan, sehingga timbul keinginan untuk membeli. 


\section{f) Strategi Komunikasi Periklanan}

Strategi komunikasi periklanan dilakukan untuk memenuhi tujuan komunikasi periklanan dengan mengambil kebijakan terhadap paduan periklanan yang terdiri dari media, kreatif, dan tata desain, antara lain sebagai berikut:

- Kebijakan Media

Melakukan perencanaan media yang mampu menjangkau target audiens yang diharapkan.

- $\quad$ Kebijakan Kreatif

Melakukan perencanaan kreatif yang bertujuan untuk menampilkan image brand Couple Distro, memperkenalkan produk, menarik perhatian, dan mempengaruhi target audiens agar melakukan tindakan untuk membeli.

- $\quad$ Kebijakan Tata Desain

Melakukan perencanaan tata desain yang bertetjuan memperoleh tata susun, layout, atau perwajahan yang memenuhi unsur informatif, estetis, efektif, dan komunikatif, sehingga mampu memenuhi tujuan komunikasi periklanan.

\section{g) Target Pasar}

Target pasar adalah orang yang memiliki minat untuk membeli, artinya jika tidak dibeli orang dengan jumlah tertentu, maka tujuan tersebut tidak tercapai. Sedangkan target audiens adalah orang yang harus dipengaruhi sehingga melakukan pembelian sehingga tujuan pemasaran dapat tercapai.

Target pasar (market) dari Couple Distro adalah remaja yang memiliki pasangan (pacar, suami/istri) dengan rentang usia 15-25 tahun khususnya berdomisili di Kota Malang dan sekitarnya. Oleh karena itu target audiens yang merupakan target media komunikasi periklanan Couple Distro.

\section{Perencanaan Media}

Dalam komunikasi periklanan, media merupakan sarana untuk menyampaikan pesan kepada target audiens. Perencanaan media menyangkut masalah biaya, sehingga dalam perencanaan media perlu diperhitungkan dengna cermat agar mampu mencapai tujuan komunikasi periklanan secara efektif dan efisien dari segi biaya.

\section{a) Tujuan Media}

Tujuan media komunikasi periklanan meliputi tiga aspek, yaitu jangkauan (reach), frekuensi (frequency), dan kesinambungan (continouity).

\section{b) Strategi Media}

Untuk mencapai tujuan media yang diharapkan, maka perlu disusun strategi media yang sesuai. Strategi media dibentuk berdasakran media habit target audiens dengan paduan media (media mix) yang terdiri dari pilihan media dan jadwal media yang disusun. Oleh karena itu diperlukan segmentasi atau penyempitan target audiens yang hendak dijangkau menjadi target audiens utama (primary) dan target audiens tambahan (secondary) kemudia dengan paduan media akan disusun menjadi strategi media komunikasi periklanan.

\section{c) Program Media}


Program media dalam perancangan ini berdasar pada konsep yang sesuai dengan kebutuhan promosi Couple Distro yang berupa in store media, sehingga program media tidak semata-mata berdasarkan pada waktu pelaksanaan kegiatan kampanye, melainkan dilaksanakan secara menyeluruh dan berkelanjutan.

\section{Perencanaan Kreatif}

a) Tujuan Kreatif

Tujuan kreatif dibuatnya perancangan ini adalah untuk menampilkan serta mengkomunikasikan Couple Distro secara kreatif, menarik, dan menyeluruh dengan memanfaatkan strategi in store media agar mampu tampil semaksimal mungkin dan secara kreatif, komunikatif serta fungsional dapat menanamkan citra Couple Distro sebagai distro yang menjual produk berpasangan dalam benak significant audience.

b) Strategi Kreatif

Strategi kreatif yang diterapkan untuk mencapai tujuan kreatif adalah dengan memanfaatkan berbagai elemen desain secara kreatif, komunikatif, dan fungsional dalam menampilkan identitas Couple Distro dengan memanfaatkan in store media agar mampu tampil semaksimal mungkin dan dapat menanamkan citra Couple Distro sebagai distro yang menjual produk berpasangan dalam benak significant audience

c) Program Kreatif

Pesan pokok yang diangkat dalam perancangan ini adalah brand communication. Perancangan berupa berbagai media secara komprehensif dapat mengkomunikasi citra Couple Distro sebagai distro yang menjual produk berpasangan. Pesan ini diupayakan mampu tertanam dalam benak significant audiens secara mendalam sehingga pada akhirnya akan tercapai brand equity dan brand loyality.

\section{d) Biaya Kreatif}

Adapun biaya kreatif terdapat pada tabel 5 dibawah ini.

Tabel 5 Biaya Kreatif

\begin{tabular}{llll}
\hline \hline No & \multicolumn{1}{c}{ Media } & \multicolumn{1}{c}{ Produksi } & \multicolumn{1}{c}{ Biaya } \\
\hline 1. & $\begin{array}{l}\text { Hang tag kaos } \\
\text { berpasangan }\end{array}$ & 1000 buah & Rp. 500.000,- \\
2. & Hang tag aksesoris & 1000 buah & Rp. 500.000,- \\
3. & Hanger kaos & 500 buah & Rp. 5.000.000,- \\
& berpasangan & & \\
4. & Kartu nama & 300 buah & Rp. 300.000,- \\
5. & Nota & 3 buah & Rp. $150.000,-$ \\
6. & Packaging Box & 500 buah & Rp. 3.000.000,- \\
7. & Stuffler & 500 buah & Rp. 250.000,- \\
8. & Shopping Bag & 500 buah & Rp. 2.500.000,- \\
9. & Flyer & 1000 buah & Rp. 300.000,- \\
10. & Dispenser Flyer & 1 buah & Rp. 20.000,- \\
\hline
\end{tabular}

\section{Visualisasi Desain}

a) Tujuan Tata Desain 
Tujuan dari visualisasi desain adalah untuk memperoleh media komunikasi visual yang sesuai dengan media promosi, dalam hal ini adalah dengan memanfaatkan berbagai media dalam toko (in store media) agar mampu tampil semaksimal mungkin, komunikatif serta fungsional dapat menanamkan citra Couple Distro sebagai distro yang menjual produk berpasangan dalam benak significant audience.

\section{b) Strategi Tata Desain}

Strategi tata desain dilakukan oleh memperioleh tujuan tata desain, yaitu desain secara kreatif, komunikatif serta fungsional dapat menanamkan citra Couple Distr dalam benak significant audience. Oleh karena strategi tata desain dilakukan selain menggunakan teori-teori desain yang ada untuk mewujudkan sebuah desain yang kreatif, komunikatif, fungsional, dan mempertimbangkan konsep pemasaran dan promosi agar tercapainya tujuan perancangan.

\section{c) Program Tata Desain}

Berikut adalah berbagai media yang secara komprehensif yang disusun berancangan berdasarkan tahap perancangan yang telah disusun sebelumnya.

\section{Hang tag kaos berpasangan}

Desain hang tag dibuat berbeda untuk produk laki-laki dan perempuan namun tetap ada unsur penyatu dari kedua hang tag tersebut, sehingga tampak berpasangan sesuai dengan konsep Couple Distro.
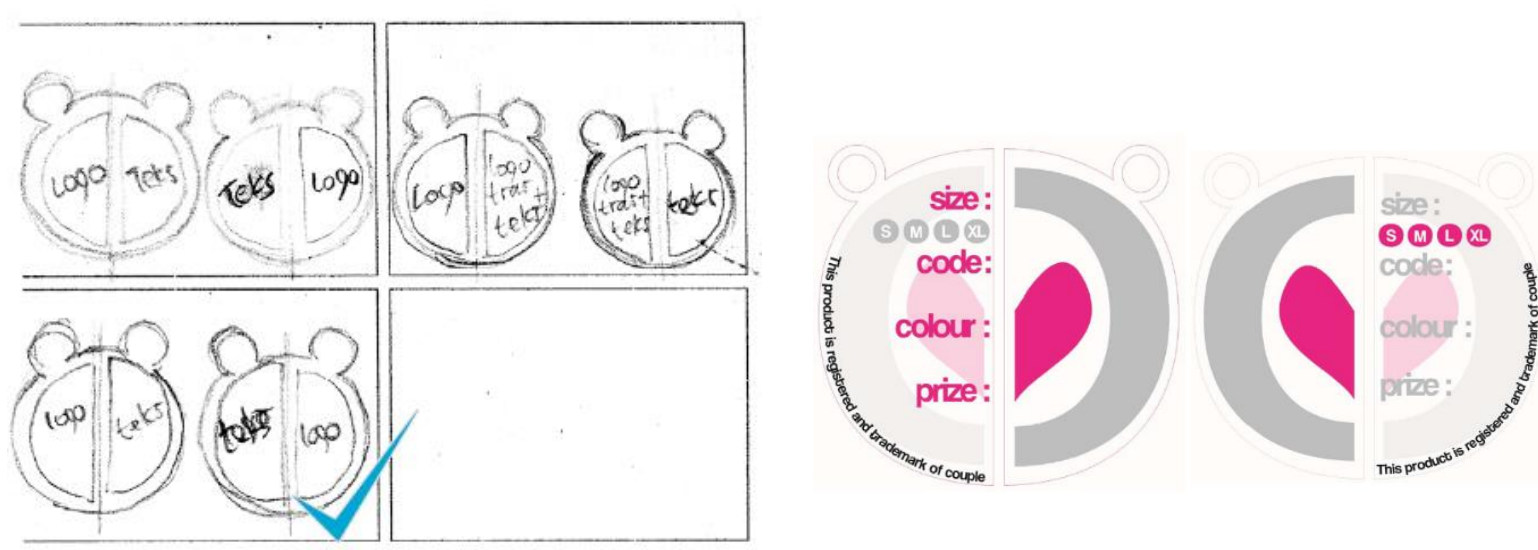

Gambar 6. Konversi Idea Layout ke Desain Final Hang Tang Kaos Berpasangan

\section{Hang tag aksesoris}

Desain hang tag aksesoris digunakan untuk produk selain kaos berpasangan, yaitu untuk berbagai produk aksesoris seperti tas, kaca mata, sepatu, dompet, dsb. 


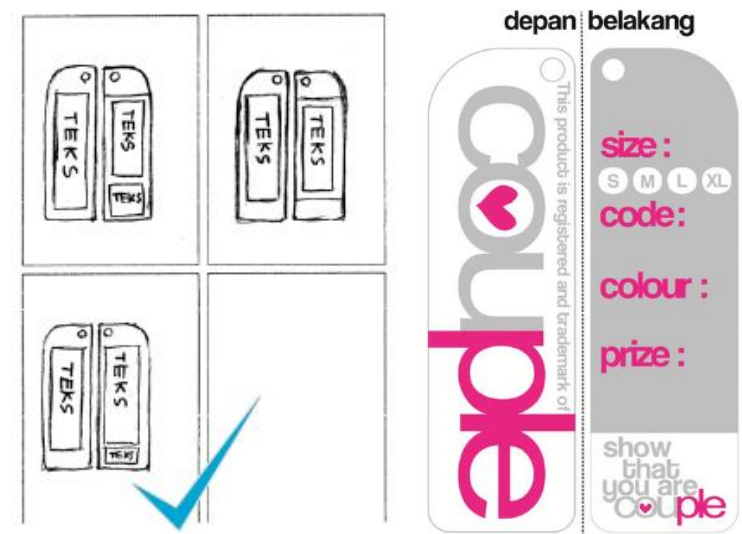

Gambar 9. Idea Layout dan Final Design Hang Tag Aksesoris

\section{Hanger Kaos Berpasangan 2 in 1}

Desain hanger untuk kaos berpasangan (2 in 1) yang dapat menampilkan produk secara kreatif, komunikatif, dan fungsional yang mampu menampilkan identitas produk kaos berpasangan.
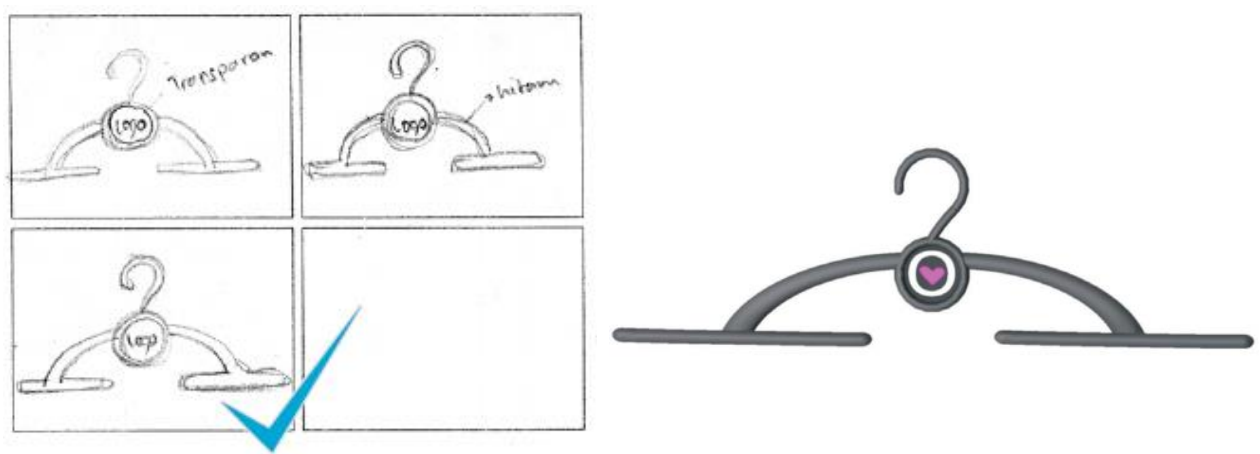

Gambar 13. Idea Layout dan Final Design Final Design Hanger Kaos Berpasangan

\section{Kartu Nama}

Desain kartu nama untuk menginformasikan keberadaan Couple Distro.
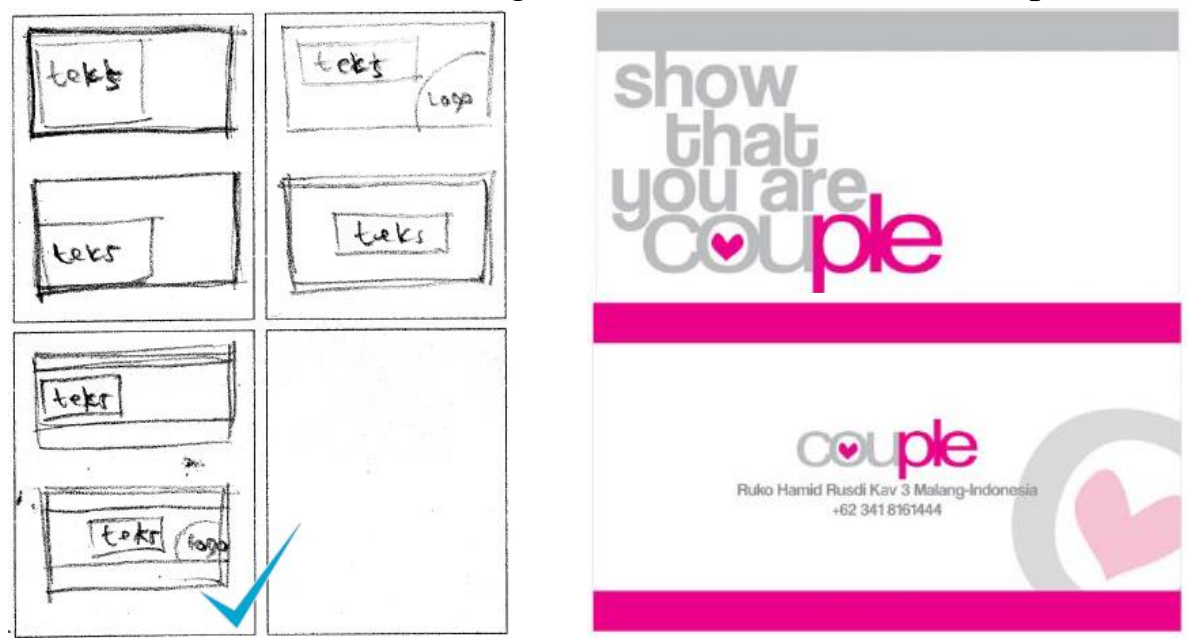

Gambar Idea Layout dan Final Design Kartu Nama 


\section{Nota}

Desain nota dibuat sedemikian rupa sesuai dengan kebutuhan untuk catatan penjualan di Couple Distro dengan menampilkan identitas Couple Distro.
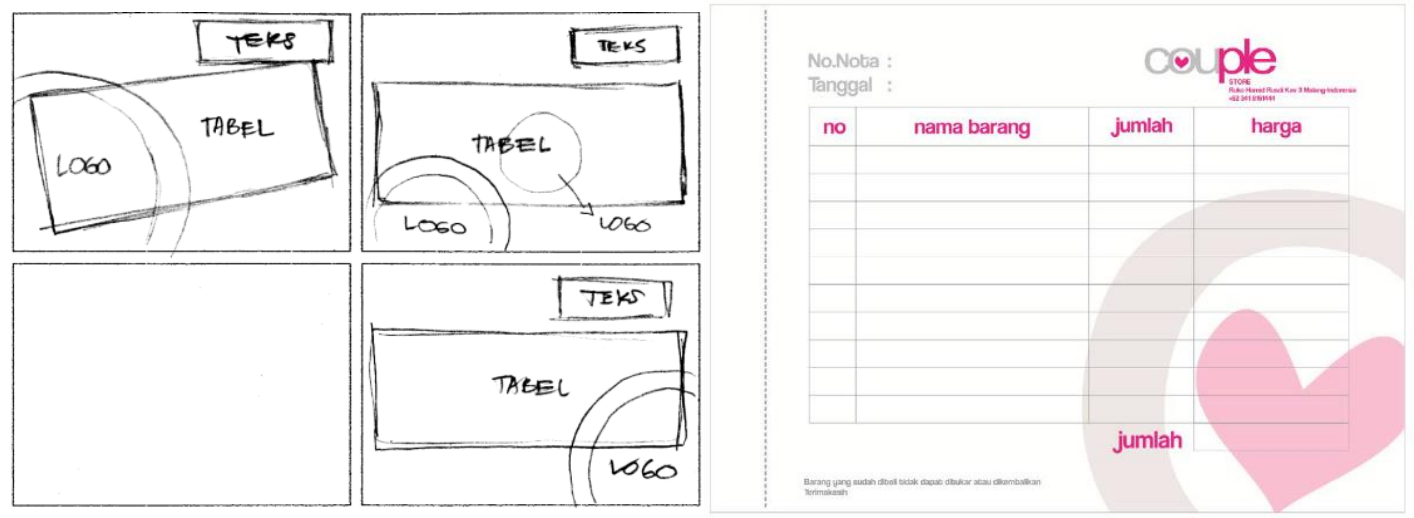

Gambar 16. Idea Layout dan Final Design Nota

\section{Packaging Box}

Desain packaging box untuk produk kaos Couple dibuat berbentuk hati seperti dalam logo Couple Distro yang dibuat sedemikian rupa sehingga dapat mengempatkan dua buah kaos sekaligus.
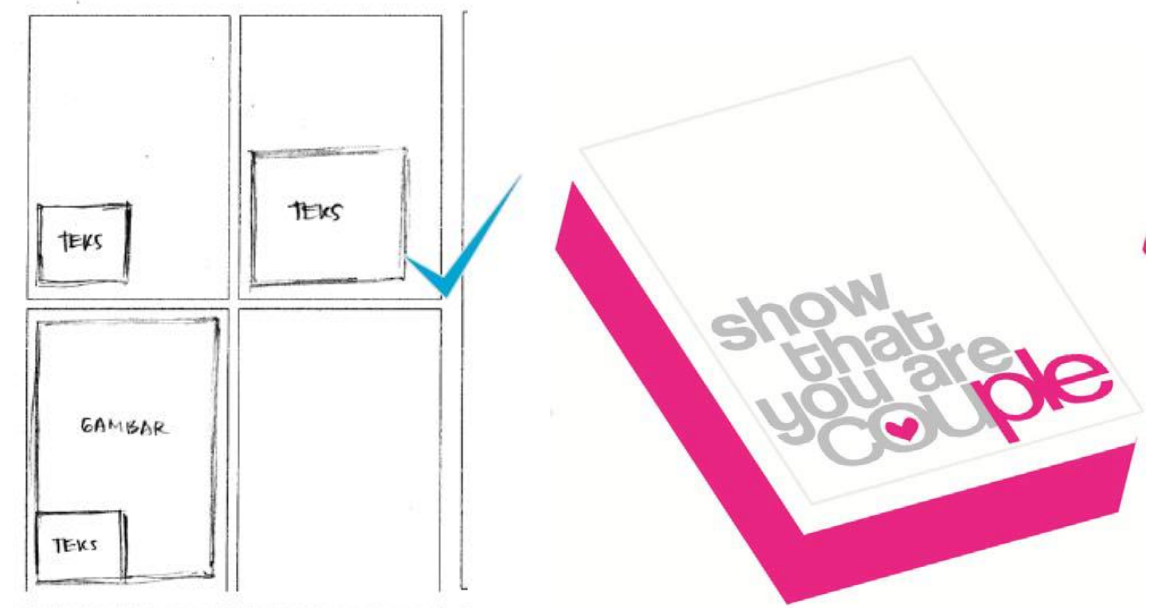

Gambar 19. Idea Layout dan Final Design Packaging Box

\section{Stuffler (sisipan dalam packaging box)}

Desain stuffler dibuat sedemikian rupa sehingga dapat memberikan informasi perawatan produk. Penempatan stuffler di dalam packaging box untuk produk kaos berpasangan. 

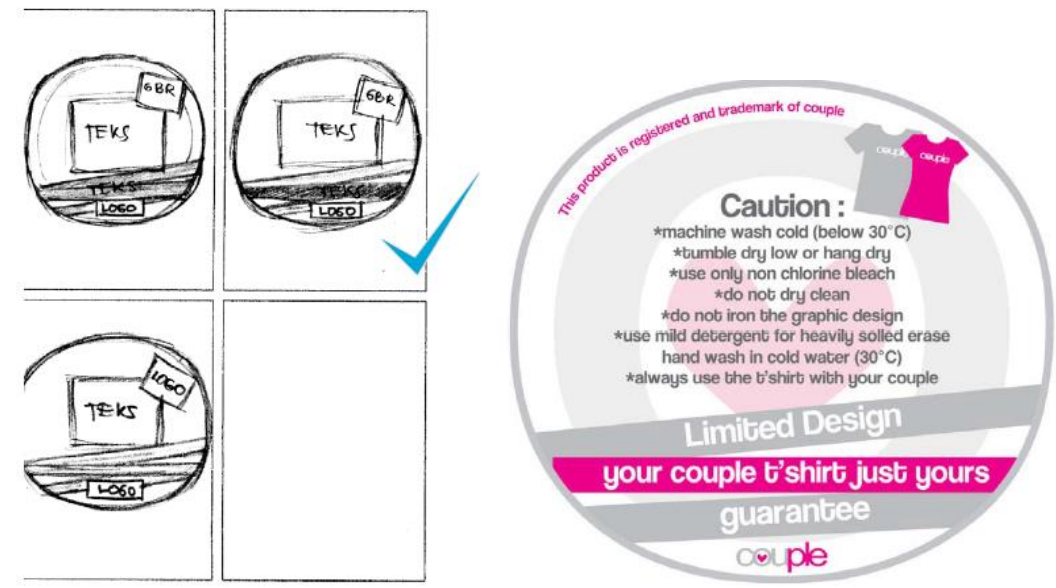

Gambar 22. Idea Layout dan Final Design Stuffler

\section{Shopping Bag}

Shopping bag berfungsi sebagai secondary packaging untuk produk yang dibeli di Couple Distro. Desain shopping bag dibuat dengan memenuhi unsur kreatif, komunikatif, dan fungsional sebagai kemasan produk Couple Distro.
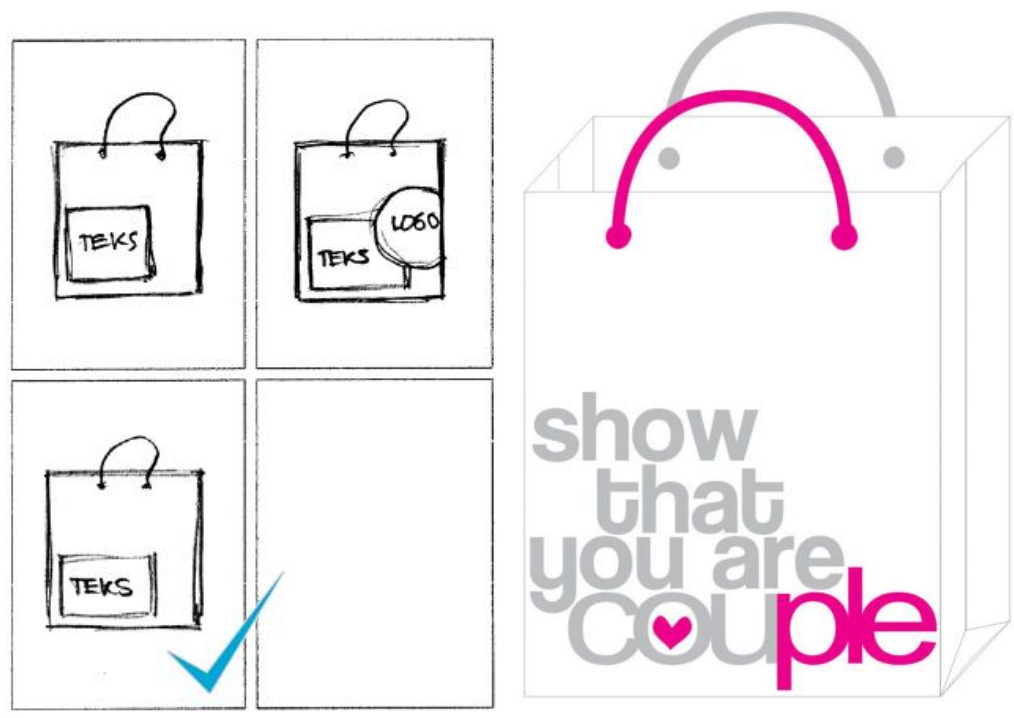

Gambar 25. Idea Layout dan Final Design Shopping Bag

\section{Flyer}

Desain flyer dibuat dengan menampilkan produk Couple Distro yang diperagakan model berpasangan untuk mengkomunikasikan produk secara menarik serta informatif. 


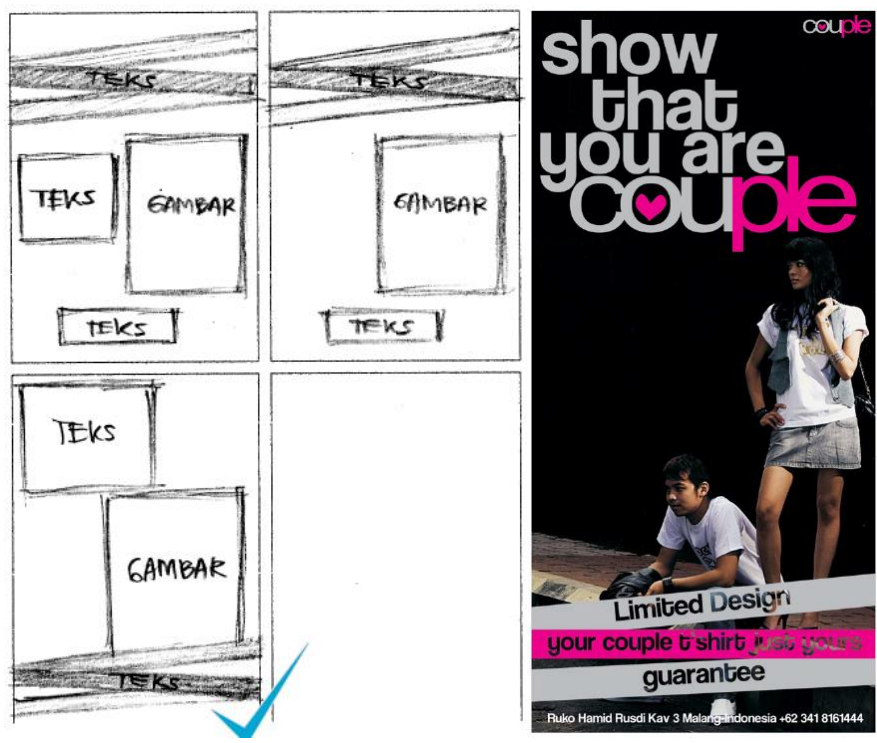

Gambar 25. Idea Layout dan Final Design Flyer

\section{Dispenser Flyer}

Desain kotak dispenser sebagai tempat peletakan flyer yang secara kreatif, komunikatif serta fungsional mampu menarik perhatian serta menampilkan identitas distro.

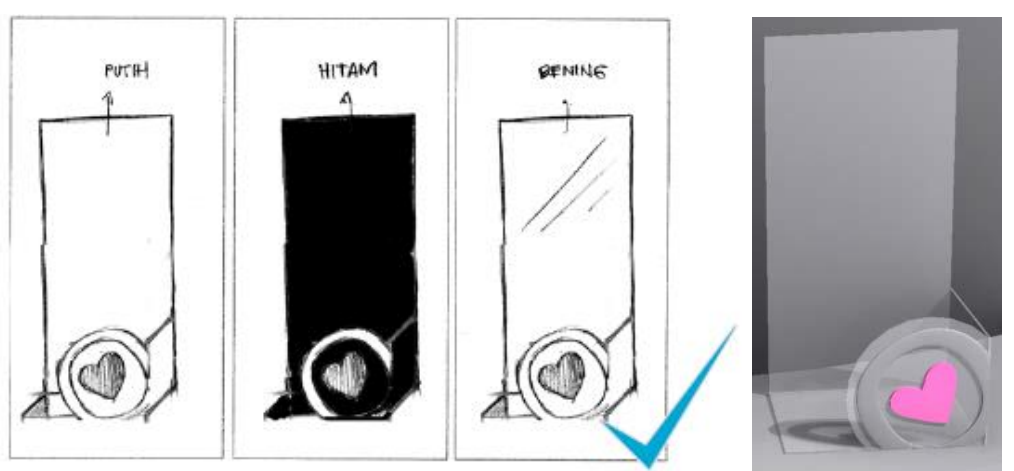

Gambar 25. Idea Layout dan Final Design Dispenser Flyer

\section{KESIMPULAN}

Couple Distro mempunyai konsep unik dan berbeda dari kebanyakan distro yang sudah ada di Kota Malang, yaitu mengusung konsep fashion apparel berpasangan. Couple Distro memiliki target amrket yang sangat spesifik, yaitu remaja berpasangan sebagai significant audience. Perancangan in store media, terdiri dari desain hang tag kaos couple, hang tag aksesoris, hanger kaos couple, hang tag aksesoris, hanger kaos couple, kartu nama, nota penjualan, packaging box, stuffler, shopping bag, flyer, dispenser flyer, pin, mini banner, $\mathrm{x}$ banner, poster in store 1 , poster in store 2 , katalog in store, seragam store assistant, desain meja kasir, fitting room, window display, interior display, dan eksterior display. Seluruh perancangan in store media telah dilakukan sesuai dengan konsep yang telah diajukan oleh penulis dan telah disetujui oleh klien. 
Diharapkan perancangan ini dapat membantu kegiatan promosi Couple Distro hingga mencapai target yang diinginkan.

\section{DAFTAR PUSTAKA}

Global, J. K., \& Jurnalistik, M. (2017). Motivasi ibu muda bergabung dengan hijabersmom community aceh. Komunikasi Global, 6, 90-101.

Hadijah, I. (2014). Upaya Peningkatan Export Drive Industri Fashion Di Era Globalisasi. Teknologi Dan Kejuruan, 37(1), 95-108.

Hakim, L. N. (2013). ULASAN METODOLOGI KUALITATIF : WAWANCARA TERHADAP ELIT Review of Qualitative Method : Interview of the Elite. Aspirasi, 4(2), $165-172$.

Hasanah, H. (2017). TEKNIK-TEKNIK OBSERVASI (Sebuah Alternatif Metode Pengumpulan Data Kualitatif Ilmu-ilmu Sosial). At-Taqaddum, 8(1), 21. https://doi.org/10.21580/at.v8i1.1163

Mashadi, M., Tinggi, S., \& Ekonomi, I. (2019). Analisa TOWS. (May). https://doi.org/10.13140/RG.2.2.16041.44646

Nugroho, N. T., Widarko, A., \& Priyono, A. A. (2016). PENGARUH KUALITAS PELAYANAN TERHADAP KEPUASAN KONSUMEN PADA DISTRO HIGAIN MALANG Oleh. 186-199.

Sanyoto, S. E. (2006). Metode Perancangan Komunikasi Visual Periklanan (p. 147). p. 147. Yogyakarta: Dimensi Press.

Sudarsono, B. (2017). Memahami Dokumentasi. Acarya Pustaka, 3(1), 47-65. Retrieved from https://ejournal.undiksha.ac.id/index.php/AP/article/view/12735 